\title{
1970 - 1971 ADALET YILININ BAŞLAMASI DOLAYISIYYLE 7 EYLÜL 1970 PAZARTESİ GÜNÜ YAPILAN TÖRENDE YARGITAY BIRINCI BAŞKANI FERRUH ADALININ KONUŞMASI
}

Sayın konuklarımı, Büyük Milletimizin faziletli hâkimleri,

Sayın arkadaşlanm,

Bu yıl 6 Eylülüin Pazar gününe rastlanması dolayısiyle Adlî yılın açlıșı törenini bugün yapıyoruz. Hâkimlerimizin, Cumhuriyet Savcılığımızın öğülmeye değer çalışmalarıyla geçen bir adalet yılını daha geride bırakmıș, her bakımdan çeşitli ve güçlü sorunları kapsayan yeni Adalet yılına girmiş bulunuyoruz. Yeni Adalet yll-. na girerken geçen yıl içinde sonsuzluğa göçen feragat sembolü hâkimlerimize, Savcılarımıza, Hak ve Adalet hizmetinde yer almış meslektașlara, Adalet görevlilerine, özellikle rahatsızlandığını sez: diği halde genel kuruldaki takrirlerine devam ve görevi başında vefat eden çok çalışkan üye Yardımcımız Nihat Tokuz'a Tanrıdan rahmet dilerim.

Hay atlarının en verimli yllarını adalet hizmetinde harcamiş bulunan Tícaret Dairesi Başkanı Sıtkı Akyazan, Ikinci Hukuk Dairesi Başkanı Kemal Ta_ı, İkinci Ceza Dairesi Üyesi Nazif Başar, Ưçüncü Hukuk Dairesi UUyesi Nezahat Göreli ve Ưçüncü Ceza Dairesi Ùyesi Cemil Millî arkadaşlarımız geçen Adalet Yılı içinde yaş haddi dolayısiyle aramızdan ayrlmıș bulunuyorlar. Kanun hükmï gereği olan bu mümtaz ve güzide hâkimlerimizin, Yargıtay'daki faal hizmetlerinden ayrlmalarma üzüntü durymamak nümkün de. gildir. Buituin meslek hayatları, doğruluk ve feragat ile geçen bu sayın arkadaşlarımıza mesleğe olan hizmetlerinden dolayı Yargıtay ve şahsım adına şükranlarımı sunarım.

Sayın dinleyicilerim,

Anayasamızda, Devlet idaresi kuvvetler ayrılı̆̆ına dayanmakta, Millet, egemenliğini Anayasanın koyduğu esaslara göre yetkili 
organlar eliyle kullanacay ilkesi bulunmakta ve 7 inci maddesinde de (yargı yetkisi) Türk Milleti adına bağımsız mahkemelerce kullanılır denmektedir. Yargının kuvvetler ayrılı̆̆ndaki önemi açıkça belli edilmiş, yasama yetkisi ile eşitliği belirtilmiştir. Nitekim 5 inci maddesinde (yasama yetkisinden) 7 inci maddesinde (yarg1 yetkisinden) bahsedildiği halde 6 mcs maddesinde (yürütme görevinden) bahsolunmuștur. Yetki ve görevin hangi organlar tarafından yerine getirileceği aynı maddelerde açılanmıștır. Kısa deyj. miyle 5 inci ve 7 inci maddeler yetkiye, 6 mcı madde göreve ilişkindir. Bununla beraber kuvvetler arasında dengeli çalışma ilkesi Anayasamız gereğidir. Yargı yetkisinin genişliğini ve bu bakımdan yargı organlarının büyük önemini bir kaç örnek vermek suretiyle belirtmek isterim. Türkiyede yaymlanan gazete, dergiler, Anayasanın 57 inci maddesindeki şartla ve (mahkeme kararı) ile kapatılabilir. Herkes, meşru bütün vasıtalardan faydalanmak suretiyle (yargı mercileri) önünde davacı veya davalı olarak iddia vẻ savunma hakkına sahiptir. Diğer bir deyimle yurttaşların can, mal, namus, şeref ve haysiyetlerinin korunması mahkemelerin givencesi altındadır. Türklerin en şerefli hakkı olan vatandaşlık hakkının alınması kararlarına karşı yargı yolu açıktır. Bu hususta son söz yargınındrr. Belli seçimler, idarenin eylem ve ișlemi, disiplin kararları yargı merciinin denetimindedir. İdare, seçilmiş organlan bir yargı mercii kararnna dayanmadan görevinden uzaklaştıramaz. Şu bir kaç örnek yargı yetkisinin devlet idaresinde, kapsamının genișliģini ve önemini göstermektedir. Anayasamız, Türkiye Cumhuriyetini (Hukuk Devleti) olarak nitelemistir. Hukuk Devletinin gưçlü dayanaklarından biri (yargı yetkisi) dir. Türk Milleti adına yargı yetkisini kullanan bağımsız mahkemeleri hâkimler temsil ederler ve Anayasanın güvencesi altındadırlar.

Hâkimler, görevlerinde Anayasaya, kanuna, hukuka ve vicdanî kanaatlarına göre hüküm verirler. Hiç bir organ, makam, merci veya kişi yargı yetkisinin kullanılmasında mahkemelere, hâkimlere, emir ve talimat veremez, genelge gönderemez, tavsiye telkinde bulunamaz.

Hâkimler azil olunamaz. Kendileri istemedikçe Anayasada gösterilen yaştan önce emekliye ayrılamaz... Kanunî istisnalar dı̣̣ında meslekten çıkarılamaz. Ancak bu kadar geniş yetki ve teminatı olan hâkimlerin o oranda sorumlulukları, ödevleri olacağından șüphe edilemez. Anayasanı 132 inci maddesinin bir anlamı da hâkimlerin tarafsız olmalanıdır. Tarafsızlık yalnız kararlarda, duruşmalar- 
da değil duruşma ve mahkeme dışındaki davranışlarında da bahis konusudur.

Kanunda yazılı haller dıșmda (hiç bir mahkeme, görev ve yetkisi içindeki davaya bakmaktan kaçınamaz), Anayasa hükmü hâkimlerin ödevleri arasındadır. Bu ödevin, yerine getirilmemesi yargı erkini olumsuz yönde etkiler.

Keza Anayasa, hâkimlerin kanunda belirtilenlerden başka ge nel ve özel hiç bir görev alamıacaklarını öngörmüștür. Bu hüküm de hâkimlere ayrı ödev yüklemekte, hâkimliğin özelliğini ifade eylemektedir. Çağımızın bilimsel, sosyal hatta teknolojik ilerlemesini izlemek, kültür seviyelerini daha çok yükseltmek, akımlarm tez ve antitezleri hakkmdaki bilgilerini çoğaltmak, demokratik ve sosyal düzenle ilgisi, uygunluğu, aykırılığı hususundaki bilgilerini daha fazla arttırmak durumundadırlar.

Anayasamızın 132 inci maddesi, hâkimlerin, hüküm verirken hangi ilke ve kurallara dayanacağını açıklamıştır.

Hâkimin uygulamalarda Anayasayı tümü ile mütalâa etmesi ve gözetmesi gerekir. Örneğin Anayasamızın temel ilkelerinden biri lâikliktir. Lâiklik temel ilkesi karşısında (vicdan hürriyetinin) sınırı olacağı şüphesizdir. Hâkim bu hususu lâiklik ve vicdan hürriyetinin niteliğinden, bunların çağımıza kadar geçirdiği tarihsel safhalara dair bilgisinden, Anayasamızın hazırliğı sırasındaki konuşma ve gerekçelerden faydalanarak takdir eder. (Kanuna) ve (Hukuka) göre hüküm vermek, kanuna, hukuk kural ve ilkelerine bağllıı̆ın ifadesidir. Hiç bir etki hâkimin vicdanî inancını sarsamaz. Hâkimin vicdanî inancına göre hüküm vermesi, Hâkimliğin en özel ve önemli niteliğidir.

Şu söylediklerimle, yargı yetkisini kullanan hâkimlere, Anayasa ile tanınan yetkiden, ödev ve görevlerinden, hâkimliğin bazı özelliklerinin bir kısmından özet olarak bahsetmiş oldum.

Inancıma göre şükranla anmak gerekir ki hâkimlerimiz, savcllarımız geleneksel tarafsızlıklarını korumuşlar, görüş ve düşünüuşlerinin Anayasa temel hak, ilke ve kurallarının korunması doğrultusunda bulunduğunu göstermişlerdir.

Sayın dinleyicilerim,

Hâkimlerin, geniş yetki ve vicdanî sorumlułı̆̆u büyük olan gö. revlerini zor koşullar altında yapmakta bulunduğunu açıllamak 
isterim. Özellikle elverişsiz yerlerde bir kısım mahkemeler Adale. tin önemi ile ölçülemiyecek niteliktedir. Araç ve gereç bakımından eksiklikleri vardır. Mahkemelerde düzenli bir kitaphk yoktur. Konut sorunu ile karşılașılır.

Hâkimlik mesleğinin ve hâkimin, hiç bir memuriyet ve memur ile kıyas olunamıyacak önemini, biraz evvelki yargı yetkisine dair konuşmamda belirtmiştim. Hâkim huzur içinde olmall, oturduğu ve çalıștı̆̆ yer şerefi ve itibariyle uygun bulunmalıdır. Elverişsiz yerlerden başlamak üzere ve bir plân çevresinde hâkim konutları ko. nusu ele alınmalı, mahkemeler Adaletin kudret ve önemi ile oranlı hale getirilmeli, araç ve gereç eksiklikleri tamamlanmalıdır. Unutmamak lâzımdır ki psikolojik bakımdan bazı maddî unsurlar, manevî unsurların bir nevi desteğini ve itimadın ilk basamağını teş. kil eder. Hukuka, sosyal konulara ilişkin yaymlar hâkimlerin, savcıların şahıslarına gönderilmeli ve Adalet Bakanlığı bütçesinde bu yolda bir bölüm ayrılmaIıdır. Anayasanı 134 üncü maddesi, (hâ. kimlerin aylık ve ödenekleri (bağımsızlık) esasına göre kanunla düzenlenir) hükmünü koymuştur. Bu hüküm memurlar hakkındaki 117 inci madde hükmü ile karşslaştırılıp bu konuya eşit anlam verìlmemelidir. Esasen Anayasada öngörülen yargı yetkisinin kapsam ve önemi böyle bir anlama yer vermez. Hâkim ödeneği bağımsızlık esasına göre düzenlenir hükmü, maddî bakımdan mülâhaza edilmemelidir. Bu hüküm yargı yetkisi ve hâkimlik mesleğinin özel. liğinin gereğidir. Yargı organlarının en yüksek mertebesinde bultrnan hâkimlerin emeklilikleri bakımından aleyhde fark vardır. Esasen ilke itibariyle Personel Kanunu dışında bulunan hâkimler için (yargı yetkisi) önemine uygun bir barem düzenlenmelidir.

\section{Sayın dinleyicilerim,}

Yurttaşlann zorluğunt çektiği bir gerçeğe de kısaca değineceğim. Gerek kamu, gerek özel hukuk konularına ilişkin kanunlarımız hükümlerinin bazı hallerde açık ve seçik olmaması, eksiklikleri bulunması yurttaşlarca güç anlaşılmalarına sebebiyet vermektedir. Yürürlü̈̆ge giren bir kanunda, kısa bir süre sonra çok kere de. ğişiklik yapılması lüzumu hasıl oluyor. Kanunlar yurttaşları șu veya bu yönden ilgilendirmekte, onlara bir takım ödev ve görevler yüklemekte olduğuna göre yurttaşın bunları anlaması icap eder. Özellikle malî hükümleri kapsayan kanunlar halk için bir sıkıntı ve zorluk teșkil eder. Kanun, ilkesine uygun bir doğrultuya girinceceye kadar, yanlış uygulamalar yüzünden yurttaş zararlara girer, vakit kaybeder, bir çok davaların konusu olur. Kanun hükmünün 
açık ve seçik oImaması yüzünden merciler arasında yazışmalara sebebiyet verilir. Bir kısim kanunların ise sosyal bünyemize uygun olmadığı uzun süre sonra anlaşılır. Halkı yakından ilgilendiren, ödev ve görev yükleyen ve kamu düzenine ilişkin kanunlarımız ele alınarak konularına göre bünyemize uygun ve Anayasa dogrultúsunda hazırlanmalidır.

\section{Sayın dinleyicilerim,}

Her yıl Yargıtay'a gelen iș sayısı artmaktadır. Yargıtay, 1969 takvim yılında ceza ve hukuk toplamı 188276 iș ile karşılaşmıs, bunun 172411 ini sonuçlandırmış, 1970 yılına 15865 iş devredilmiştir. 1970 yılının altı aylık döneminde ceza ve hukuka gelen işin topla. mı 106763 e ulaşmış, bunun da 89849 u çıkarılmıștır. Ceza ve Hukuk Genel Kurullarına gelen işler bu sayıların dıșındadır.

Mesai saatleri gözetilmeden feragatle olağan üstü bir gayreti yansıtan bu sayılar, Yüksek Hâkimlerin ve onların yardımcılarının nasıl yıpratıcı bir çalışma düzeni içinde bulunduklarını gösterir. $\mathrm{Bu}$ yoğun çalışmaya çalışma yerlerinin elverişsizliğini de eklemek gerekir. Gerçekten Yargıtay binası rahat bir çalıșma yeri olmaktan uzaktır. Bir Yargitay Hâkimine ayn bir oda verilememekte, ihtiyaçların bir kısmı yazışmalara, yapılan teşebbüslere rağmen gereği gibi ve zamanında sağlanamamaktadır. Yargıtay'ın ya bağımsız bir bütçesi olmalı veya Adalet Bakanlığı bütçesinde, Yargıtay'ın her bakımdan ihtiyaçlarını karşılayacak surette belli bir bölüm ayrılmalıdır. Yargıtay Konusunda geçen Adalet yılı açılış konuşmamda sözünü ettiğim bir yöne tekrar değineceğim. Her yıl nüfusumuzun çoğalması, ekonomik ve sosyal ilişkilerin artması, değiş. mesi, yeni kanunların yeni hükümler getirmesi, yeni iș ve davaların meydana gelmesine sebep olacak, iş hacmi her yıl artmakta devam edecektir. Ötedenberi olduğu gibi buna karșı daireler sayısının belirli sürelerde çoğaltılması yoluna gidilecektir. Ancak daire. ler sayısını artırma geçici bir tedbir olabilir. Başka memleketlerde daire ve Ùye sayısı bu kadar çok olan bir yüksek mahkeme bulunacağın tahmin etmiyorum. Yargıtay'ın esas görevi, bütün yurtta kanunlarm bir anlamda ve șekilde uygulanmasını sağlamak, işi hukukî yönden incelemek olduğu halde arada üst mahkemelerin mevcut olmaması yüzüinden maddî hukuk bakımından da gereklj inceleme yapılmakta ve bu hal gecikmelerin, iş birikmesinin aslî sebebini teşkil etmektedir. UUst Mahkemeler (İstinaf Mahkemeleri) kurulmadıkça daire ve Üye sayısının bir noktada duracağı düșünü. lemez. Artırma zaruretinin önüne geçilemiyecektir. (Istinaf Mah- 
kemelerinin) kaldırılmasından sonra geçen uzun sürede birçok değerli hâkimler yetişmiştir. Bu itibarla üst mahkemeler için kifayetli hâkim sayısının azlı̆ı̆ ileri sürülemez. İstinaf Mahkemelerinin kaldırnlmasına sebep olan koşullar da bugün mevcut deģildir. Bünyemize uygun ve bazı sakıncalar giderilmek suretiyle üst mahkemelerin kurulması mümkündür. Dolayısiyle Yargitay'daki iş hacmi azalacak, işler daha süratle çıkacak ve bir kısım davaların üst mahkemelerde sonuçlanması, yurttaşların kül. fetini azaltacaktur.

Sayin dinleyicilerim,

Barolar Adalet cihazının işlemesinde etkili birer organ, Avukatlar Adaletin meydana çıkarılmasında, bir hakkın yerine getirilmesinde Adalete, Hâkime yardımcı meslektaşlardır. Hâkim ve avukat arasındaki ilişkiler, daima Adalete, hakka olumlu yönde etkili bir ilişsi olmalıdır. Avukatların başka mahallerde veya mahkemelerde işleri olduğu nazara alınarak duruşma saatleri belli fasılalarla ayrılmalıdır. Diğer yönden Anayasa gereği yargı yetkisini kulla. nan ve mahkemeyi temsil eden hâkime karşı yurttaşların saygi ve itimadını sarsacak davranışlardan sakınmak ve görevinin ağıłığı. $\mathrm{n}$, insan takatinin üstünde çalışma durumunda bulunduğunu gözönünde tutmak bir meslektaşlık borcudur. Aynı suretle avukatın da, bir hakkın yerine getirilmesi için çaba sarfeden ve savunma hakkının temsilcisi durumunda olan bir meslektaş olduğu unutul. mamalıdır. Adalet cihazının işlemesinde Baroların önemli organlar olduğunu ifade etmiştim. Mücerret bu yön Barolann bağımsız bir kuruluş olmasını gerektirir. Avtłkatlık Kanununda bu yönï aksatan hükümlerin düzeltileceğine, Türkiye Barolar Birliğinin, Dünya Barolanı arasında lâyık olduğı yeri alacağına inanmaktayım.

\section{Sayin dinleyicilerim,}

Adalet sorun ve konularının tümünün bir Adalet yilı açılıșı konuşmasında ele alınması toplantınm niteliği bakımından mümkün olamayacağ takdir buyurulur. Geçen konuşmamda sözünü ettiğim fakat halâ çözümlenmemiș konulardan bir kısmını yine özet olarak tekrar ele almak lüzumunu hissettim. Gerek kamu hukukunda ge. rek özel hukukta ilke ve kural olarak adaletin ve hakkın sürat ve isabetle yerine getirilmesi bazı koşullara bağlıdır. Ylllar süren bir dava hak sahibi için, măgdur ve hatta suçlu için bir üzüntü kaynağı olur. Adalete karşı yurttaşın güvenini sarsar. Davalarda sürati sağlayacak tedbir ve kanunların biran evvel hazırlanmasına ve ha- 
zırlanmış bulunanların yüksek meclisten çıkarılmasına gayret gösterilmelidir. Bu tedbir ve kanunların neler olabileceği geçen konuşmamda ifade edilmiştir.

Hâkimlerle birlikte feragatle ve çoğu yerlerde geceleri de çalışmak zorunda kalan zabıt kâtiplerinin, Adalet memurlarının maddi durumları düzeltilmelidir. Ùzïntü ile söyliyeyim ki Personel Kanunu bu memurların özel durumunu gözetmemiştir. Hâkimler Kanunu ve gerekli olan Hâkimler baremi sırasında zabıt kâtipleri ve adalet memurları bu kanunlarda yer almalidır.

Adalet düzeni ile ilgili bir konu olan adlî zabıtanın kurułmas1 geciktirilmemelidir.

1969 Adalet yulı açlışı konuşmamda üzerinde önemle durduğum, memleketimiz için maddî ve manevî ağır zararlar veren tra. fik konusu endişeyi gerektiren bir hal almıştır. Ara sıra sıklaştırılan kontrollar, durdurulan arabalarda sürücülerden ehliyetname ve gerekli belgelerin aranmasından ibaret kalmamalıdır. Sürat kontrolu yapılmalı, araçların yollarda tüzüğe aykırı ne gibi eylem ve hareketlerde bulunduğu kontrola tabi tutulmalıdır. Kazaların çoğu, sürücülerde lüzumlu belgelerinin bulunup bulunmamasından değil (seyrüsefer) kontrolunun eksikliğinden ileri gelmektedir. Olay. lara çoğunlukla kamyonların sebebiyet verdiği, kamyon sürücüsü arabasının niteliğine dayanarak nizamlara riayetsizlikte kendisi için tehlike görmediği, esaslı bir kontrolda ortaya çlkacak bir vakıadır. Kontrola çıkan trafik araçlan belli olduğundan bir çok hallerde kontrollar gereken etkiyi yapmamaktadır. Bu konunun ayrıntılarma girmeye toplantımızın niteliği müsait değildir. Trafik Kanun ve tïzügüunde gerekli değișikliklerin yapılması, Trafik Zabıtasının artırılması, Kanun ve Tüzüğün müsamahasız uygulanması gibi ön tedbirlerin bir an önce alınması zorunluğu meydandadir.

Son zamanlarda bahsettiğim noktaların dikkate alındığını ve bu alanda çalışmalara başlandığını memnuiyetle öğrenmiş bulunuyoruz. $\mathrm{Bu}$ husustaki uygulamaların aksatılmadan ve sïrekli olarak yürütülmesi lüzumuna işaret etmek isterim.

Sayın dinleyicilerim,

Anayasamıda önemle belirtilen bir konuya da özet olarak değineceğim.

Ormanlarımızın yurt ölçüsündeki değer ve önemi şüphe götürmez bir gerçektir. Denebilir ki her geçen gün, tehlikeyi artırmakta, 
yurdun geleceği için endişe vermektedir. Yurt savunmasının, ekonomisinin, toplum sağlığının, sosyal düzenin bir yönden ormanlarımızın geleceğine bağlı bulunduğunu söylemekte mübalâa olmasa gerektir. Orman suçlarının işlenmemesini, azalmasını öngörecek surette çă̆ımızın görüşüne, bilim ve tekniğe uygun ve yalnız yurt ve toplum yararını ve geleceğini gözeten amaç ile tedbirleri ivedilikle almalı ve Anayasamızın bu hususțaki hükümlerini gözden uzak tutmamalıyı.

Sayın konuklarımız ve değerli arkadaşlarım,

1970-1971 Adalet yılını kapsayan konuşmamda Adalet işlerine ilişsin konu ve sorunların bir kısmına değinmiş bulunuyorum. Hukuk düzeni içinde yargı, düzenin bir bölümünü, fakat en önemli bölümünü teşkil eder. Anayasanm 2 inci maddesi Türkiye Cumhuriyetini bir hukuk devleti olarak nitelemiștir. Bu bakımdan sorunların, konuların hukuk yoluyla, hukuk düzeni içinde çüzümlenme. si Anayasanıin öngördüğ̈ii bir ilkedir. Anayasamızda öngörülen ilkeler, çă̆daş uygarlı̆̆ın vazgeçilmez ilkeleridir. Bunların tümü ile gerçekleşmesi ve varhı̆̆ımızın temeli olan Atatürk inkilâplarmın korunmașı yolunda hukukun üstünlüğai ilkesine riayet ederek, bütün Milletçe görevli sayılırı.

Konușmama son verirken bu toplantıya şeref veren ve beni dinlemek sabır ve lûtfunu gösteren sayın konuklarımıza, sayın Hâkim ve Savcı arkadaşlarıma teşekkürlerimi sunarım. Ulvî Adalet hizmetinin görevlilerine yeni Adalet yılında başarnlar dilerim. 